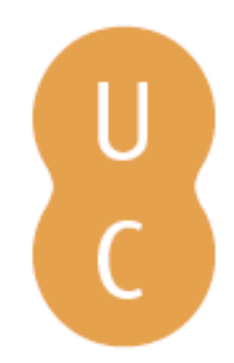

\title{
pommalina
}

\section{As políticas educativas como políticas sociais: mapeando transformações no mandato para a educação de adultos hodierna}

\author{
Autor(es): $\quad$ Barroso, Rosanna \\ Publicado por: Imprensa da Universidade de Coimbra \\ URL \\ persistente: URI:http://hdl.handle.net/10316.2/31229 \\ DOI: $\quad$ DOI:http://dx.doi.org/10.14195/978-989-26-0228-8_3 \\ Accessed : $\quad$ 26-Apr-2023 16:10:45
}

A navegação consulta e descarregamento dos títulos inseridos nas Bibliotecas Digitais UC Digitalis, UC Pombalina e UC Impactum, pressupõem a aceitação plena e sem reservas dos Termos e Condições de Uso destas Bibliotecas Digitais, disponíveis em https://digitalis.uc.pt/pt-pt/termos.

Conforme exposto nos referidos Termos e Condições de Uso, o descarregamento de títulos de acesso restrito requer uma licença válida de autorização devendo o utilizador aceder ao(s) documento(s) a partir de um endereço de IP da instituição detentora da supramencionada licença.

Ao utilizador é apenas permitido o descarregamento para uso pessoal, pelo que o emprego do(s) título(s) descarregado(s) para outro fim, designadamente comercial, carece de autorização do respetivo autor ou editor da obra.

Na medida em que todas as obras da UC Digitalis se encontram protegidas pelo Código do Direito de Autor e Direitos Conexos e demais legislação aplicável, toda a cópia, parcial ou total, deste documento, nos casos em que é legalmente admitida, deverá conter ou fazer-se acompanhar por este aviso.

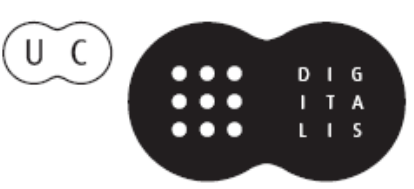




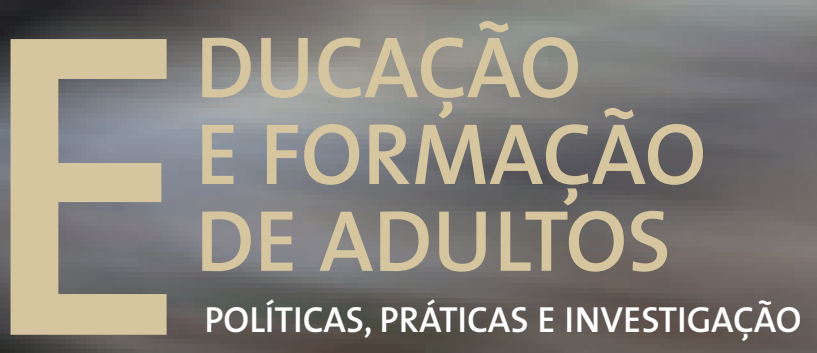

Luís Alcoforado • Joaquim Armando G. Ferreira António Gomes Ferreira • Margarida Pedroso de Lima Cristina Vieira • Albertina L. Oliveira • Sónia Mairos Ferreira 


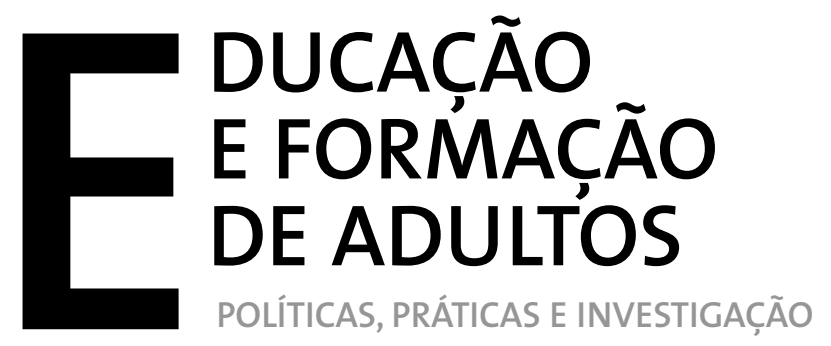

Luís Alcoforado • Joaquim Armando G. Ferreira António Gomes Ferreira - Margarida Pedroso de Lima Cristina Vieira • Albertina L. Oliveira • Sónia Mairos Ferreira 
EDIÇÃo

Imprensa da Universidade de Coimbra

URL: http://www.uc.pt/imprensa_uc

Vendas online: http://www.livrariadaimprensa.com

CONCEPÇÃO GRÁFICA

António Barros

Pré-Impressáo

SerSilito-Empresa Gráfica, Lda

EXECUÇÃo GRÁFICA

SerSilito-Empresa Gráfica, Lda

ISBN

978-989-26-0136-6

DePósito LEgaL

$340309 / 12$ 



\title{
As Políticas Educativas como Políticas Sociais: mapeando transformaçóes no mandato para a Educaçáo de Adultos Hodierna
}

\author{
Rosanna Barros \\ Universidade do Algarve
}

A reforma do Estado-Providência, nas suas várias configuraçóes, que ocorre no centro do sistema mundial desde a década de setenta do século XX, tem procurado, no geral, obter uma retracção das políticas sociais e dos direitos adquiridos nos anos dourados de vigência do modelo de Keynes-Beveridge. Ora, sendo os pressupostos da nova direita, aquela matriz político-ideológica que tem adquirido maior hegemonia na condução deste processo global de redefinição do papel do Estado, não surpreende, pois, que a esta retracção das políticas sociais corresponda também uma reestruturação do processo de elaboração das políticas educativas, em moldes que apontam para uma revisão (substituição?) dos pressupostos humanistas presentes na tradição da Educação de Adultos do pós-guerra, vinculada, como se sabe, sobretudo pela UNESCO. Efectivamente, como afirma Lima, "do ponto de vista das políticas sociais e de educação vêm ganhando crescente protagonismo as perspectivas de tipo tecnocrático e racionalizador, com a desvalorização do domínio público e com os apelos de inspiração gerencialista e neo-científica em educação” (Lima, 2000, p. 238). Embora mais centrados num tipo particular de práticas de educação de adultos, a formação pós-escolar, também Dubar e Gadéa ao analisar, para o caso francês, as políticas públicas produzidas para este subsector, entre 1959 e 1993, constatam que actualmente "os imperativos económicos dominam mais do que nunca o campo da formaçáo tornada instrumento da manutenção da empregabilidade dos assalariados” (Dubar e Gadéa, 2001, p. 147).

Apesar de ser este o sentido, amplamente identificado na literatura acerca da globalização neoliberal, para as transformaçóes ocorridas desde o pós-guerra, esclarecemos aqui, e desde já, que não as consideramos inevitáveis, ao contrário do que oficialmente fazem, repetidamente, supor os discursos públicos hegemónicos, e um certo pós-modernismo reaccionário, como lhe chamou Paulo Freire, de legitimação simbólica do sentido das mudanças introduzidas nas políticas sociais e nas políticas educativas. Desde uma perspectiva crítica não só as políticas são vistas como o resultado deliberado de opçóes tomadas nas instâncias onde se localiza o poder de decisão, não sendo portanto inevitáveis, como também, em termos sociológicos, está bem documentado que a introdução de alteraçôes, por via de políticas do Estado, nos contextos institucionais, quer se trate de uma reforma inovadora ou de uma estratégia de mudança, implica usualmente distintos tipos de comportamentos face aos processos de mudança, que de acordo com Lima, podemos teoricamente considerar serem de três tipos principais: comportamentos de participaçáo activa; comportamentos de passividade; e comportamentos do tipo travão (cf. Lima, 1994, p. 69). No mesmo sentido vão as observaçóes de Antunes quando refere que "consenso, aceitaçáo renitente e oposição surda ou declarada não são dados à partida mas o resultado de processos políticos e ideológicos, morosos e delicados, que envolvem tanto a acção e autoridade do Estado como movimentaçóes e alianças ao nível dos agentes e grupos sociais envolvidos" (Antunes, 1998, p. 28). Assim, na problemática que equaciona os processos de transformação social, há a considerar quer as características do próprio processo de produção das políticas 
estatais, quer os termos e pressupostos segundo os quais se possessa a compatibilização das estratégias de gestão da relação conflitual entre a actividade do Estado e os problemas estruturais das formaçóes sociais do capitalismo avançado.

É precisamente neste sentido que Lenhardt e Offe (1984) interpretam a política social, e os processos de inovação nesta área, como o conjunto diversificado de instituiçôes, estratégias e medidas de intervenção criadas pelo Estado para, em boa medida, responder aos problemas estruturais presentes na necessidade de conciliar as exigências e necessidades do capital com as exigências e necessidades do trabalho, ou seja, para tentar resolver o metaproblema da "constituição e da reprodução permanente da relação do trabalho assalariado" (Lenhardt e Offe, 1984, p. 32). As medidas de políticas sociais, assim entendidas, tratariam fundamentalmente de operar uma conciliação dilemática entre os diversos constrangimentos que enformam o próprio campo de actuação do Estado Capitalista Democrático, e também neste sentido, podem ser interpretadas como uma forma de manter em níveis politicamente manejáveis os conflitos e riscos de integração social, de modo a tornar viável a "praticabilidade das instituiçôes sócio-políticas existentes" (id., ibid., p. 37). É a partir desta perspectiva que se podem conceber as políticas sociais do Estado como estratégias de regulação social, que tanto possibilitam a valorização privada do capital, apoiando o processo de acumulação, como facilitam a continuidade do trabalho assalariado livre, mediante a indução de um consenso alargado que legitime a ordem vigente, ou seja, a manutenção de um dado modo de organizar quer a produção quer o consumo, que garanta a sua aceitaçáo e desde logo o afastamento de possíveis ameaças desestabilizadoras. Entendendo que a acção governamental reflecte as escolhas que são tomadas num quadro conflitual como o que daqui deriva, Oliveira e Duarte, salientam a função de regulação focalizada que a política social desempenha precisamente ao intervir "no hiato derivado dos desequilíbrios na distribuição em favor da acumulação capitalista e em detrimento da satisfação de necessidades sociais básicas” (Oliveira e Duarte, 2005, p. 283).

Enquanto partes constitutivas das políticas estatais as políticas de educação pública, bem como as políticas de saúde pública ou as políticas de habitação social, podem ser pensadas como a expressão, em esferas particulares da vida em sociedade, da estratégia de gestáo do conflito estrutural que as políticas sociais têm como objectivo principal procurar compatibilizar. Assim sendo, a partir da perspectiva proposta por Lenhardt e Offe, em que "a socializaçáo através do trabalho assalariado tem, de fato, como pré-requisito, que as formas de existência externas ao mercado de trabalho, sejam organizadas e sancionadas pelo Estado" (Lenhardt e Offe, 1984, p. 17), cria-se a possibilidade de argumentar, como nota Antunes (1998), que o campo específico das políticas educativas, enquanto domínio das políticas estatais, "não está 'a serviço' das necessidades ou exigências de qualquer grupo ou classe social, mas reage a problemas estruturais do aparelho estatal de dominação e de prestação de serviços" (Lenhardt e Offe, 1984, p. 39), pelo que a satisfação dos interesses do Estado, mediante medidas de racionalização interna ao sistema, podem implicar efeitos externos, sobretudo quando "as inovaçóes no campo da política social - novas leis, regulamentos e procedimentos - modificam explicita e claramente as relaçóes de favorecimento/desfavorecimento entre certas categorias de pessoas" (id., ibid., 38). Há aqui uma margem para interpretar, como fez Althusser (1970), os sistemas de educação escolar como uma vertente ideologicamente estratégica dos aparelhos do Estado, contexto em que se pode de igual modo afirmar, como assinala Jarvis, que todas as formas de educação são, até um certo ponto, também instrumentos da política social, isto é, "a política social sobre o sistema educativo, independentemente das aspiraçóes e objectivos 
educativos dos educadores, trata de como o governo, nacional e local, pode utilizar a educação dentro do sistema social mais amplo" (Jarvis, 1989, p. 199). As políticas de educação pública seriam, nestes termos, eminentemente ideológicas e normativas.

Ora, é com base neste enquadramento teórico geral, que percepciona a política educativa como política social, que se tem vindo a alicerçar uma perspectiva interpretativa que sugere o interrelacionamento dos processos de elaboraçáo das políticas educativas com os processos de formulação das políticas sociais, pensando-se as primeiras, como propóe Colin Griffin, enquanto "uma parte integral de uma política socio-económica mais ampla" (Griffin, 2002, p. 42). Assim, e adoptando neste texto, o essencial dos modelos teóricos de produção de políticas sociais, nos termos propostos por este autor, encontramos espaço para argumentar que no campo da educaçáo de adultos a transição do paradigma da educação permanente para o paradigma da aprendizagem ao longo da vida é parte integrante e constituinte de um processo de mudança social em curso, no qual se dá a redefinição do papel do Estado Capitalista Democrático na gestáo do conflito estrutural entre capital e trabalho. Sendo que a resposta a este conflito em contexto de Estado-Providência significa uma produção de políticas sociais nos moldes do que Griffin (1999a) designou por modelo progressivo (social democrata), enquanto que a resposta em contexto de Estado Neoliberal significa uma produção de políticas sociais nos moldes do que Griffin (1999b) designou por modelo reformista (neoliberal). Ou seja, o que sustentámos é que: na relação entre Estado e educação de adultos, em que há um carácter bilateral de mútua interdependência (cf. Pöggeler, 1990, pp. 15-20), é possível teorizar linhas de reciprocidade, que não sendo inequívocas nem lineares, fazem-nos mesmo assim perceber claramente uma tendência, percepcionada a partir da realidade do centro do sistema mundial, para encontrar dois tipos ideais de associaçóes entre, por um lado, o modelo de Estado-Providência a que correspondem políticas sociais de pendor progressivo social-democrata, a que está ligado um campo de educação de adultos de tipo humanista e democrático, inscrito no paradigma da educação permanente; e por outro lado, o modelo de Estado Neoliberal a que correspondem políticas sociais de pendor neoliberal (típicas da nova direita), a que está ligado um campo de educação de adultos de tipo tecnocrático e vocacionalista, inserto no paradigma da aprendizagem ao longo da vida. A forma como o Estado projecta a sua acção, num e noutro caso, pressupóe um entendimento substancialmente distinto para o papel que a política social, e neste caso a educação de adultos como um dos seus instrumentos, pode desempenhar na "conciliabilidade problemática" (Lenhardt e Offe, 1984, p. 37), necessária ao funcionamento do Próprio Estado, entre as exigências e necessidades dos vários grupos e classes sociais em interacção nas formaçóes sociais e os imperativos do processo de acumulação capitalista.

No contexto da transformação do papel do Estado, a que nos temos vindo aqui a referir, as funçóes da educação e sobretudo os pressupostos com que se elaboram as políticas públicas de educação de adultos encontram-se, de acordo com as análises de Colin Griffin (1999a, 1999b), e como assinala Lima (2003, 2004), substantivamente dependentes de três tipos de modelos de produção de políticas sociais, que pela relevância que possuem serão seguidamente explicitados.

Assim sendo, o modelo progressivo social-democrata (cf. Griffin, 1999a, pp. 329-342) diz respeito a um contexto em que há uma forte tónica no papel redistributivo do Estado e nas responsabilidades governamentais na elaboração de políticas sociais que promovam a democracia e a justiça social. Envolve um modo de entender as políticas estatais que 
implica a salvaguarda da prestação, com uma tendente qualidade e cobertura universal, dos serviços públicos em geral, mas especialmente dos relacionados com a educação. Nesta linha a educação de adultos é vista como uma política social essencial, que conheceu a sua forma mais avançada no caso dos países escandinavos, e no quadro da qual se promove principalmente a afirmação de direitos, de justiça redistributiva e de participação cidadã democrática. O reconhecimento da sua função de promoção de bem-estar social é visível no significativo apoio estatal dado ao sector através de uma vincada provisão pública para muitas das suas iniciativas. Trata-se, de resto, da matriz defendida historicamente sobretudo no seio da UNESCO, e bem divulgada pelas suas iniciativas, tais como por exemplo: o Relatório Faure ou as diversas Conferências Internacionais realizadas na área (as seis CONFINTEAS), em que a educação de adultos é entendida como um bem colectivo e como um direito fundamental, inscrita nos pressupostos de uma Educaçáo Permanente, tal como foi concebida, sensivelmente há trinta anos, quer por Robert Hutchins quer por Paul Lengrand. De acordo com Torres, foi neste contexto sócio-político, cujo auge se deu no pós-segunda guerra mundial, que "o planejamento educacional desempenhou um papel central nas concepçóes do Estado intervencionista do bem-estar, um Estado que foi necessário para controlar as tendências autodestrutivas do crescimento capitalista" (Torres, 2001, p. 50), significando uma expansão educacional notável e sem precedentes, e uma época de ouro na história da educação de adultos.

O segundo tipo de produção de políticas sociais, refere-se ao modelo de política social crítico (cf. Griffin, 1999b, pp. 447-451) que diz respeito a um contexto em que prevalecendo a defesa dos princípios da matriz político-ideológica de tipo social-democrata, se lhe tece, não obstante, significativas críticas que se relacionam, no entender de Torres, com uma desilusão geral com o liberalismo social, na medida em que sobressaem na literatura crítica e radical da época "a falência da teoria educacional funcionalista [que] remonta à sua incapacidade de explicar plenamente as causas da desigualdade e os problemas das desigualdades de oportunidades, e menos ainda de sugerir uma estratégia plausível para lidar com o papel do processo educacional na perpetuação das desigualdades sociais" (Torres, 2001, p. 52). A crise mundial da educação escolar, do início da década de setenta, está inscrita neste contexto, que de um modo geral resulta, também, destas críticas que são dirigidas ao carácter centralizado e burocrático dos sistemas nacionais de educação, típicos do aparelho administrativo do modelo do Estado-Providência, ao qual são igualmente tecidas diversas críticas que visam maioritariamente o único objectivo geral de alargar o potencial humanista contido nas suas políticas sociais, para alcançar, no caso da educação de adultos, uma ainda maior igualdade de acesso e sucesso escolar e de justiça social, apelando para uma descentralização das decisóes democraticamente operada com a sociedade civil. Aliás, este ethos geral de crítica ao modelo de providência social, paradoxalmente, será aproveitado pela nova direita, precisamente para empreender a sua reforma, mas em moldes muito distantes dos pretendidos no modelo de política social crítico.

Desta forma, o modelo de reforma social neoliberal (cf. Griffin, 1999b, pp. 431-447) diz respeito a um contexto de crise do Estado-Providência e da resposta de cariz neoliberal à crise do fordismo, num novo modelo de produção de reformas políticas sociais em que emergem os pressupostos principais que caracterizam o Estado Neoliberal. Transita-se assim, neste modelo, para um contexto de deslegitimação do serviço público tradicional, cujas características de gratuitidade e de universalidade passam a ser consideradas como obstáculos à responsabilização individual. Envolve um modo de entender as políticas estatais 
que implica a salvaguarda prioritária da competitividade, e a crescente promoção da mercantilização dos serviços anteriormente afectos ao fornecimento colectivo de direitos sociais. Nesta linha, a educação de adultos é vista cada vez menos como um instrumento de uma política social de promoção democrática da justiça e igualdade sociais, para ser entendida cada vez mais como uma estratégia de reforma do Estado keynesiano e um mecanismo de combate à exclusão social, ou, mais concretamente, aos efeitos perturbadores da paz social que resultam directamente da globalização económica neoliberal, com a crescente institucionalização da acumulação flexível, que torna típica a relação salarial pós-fordista e o desemprego estrutural que lhe está subjacente. $\mathrm{O}$ reconhecimento da sua função estratégica como solução para a competitividade das economias avançadas é visível no apoio dado pelas instâncias supranacionais aos programas de educação de adultos inscritos numa matriz vocacionalista, defendida especialmente no seio da OCDE e da Uniáo Europeia, em que a educaçáo de adultos é entendida como um bem de consumo passível de operar segundo a lógica do mercado, um entendimento que a inscreve inequivocamente de agora em diante nos pressupostos de uma aprendizagem ao longo da vida. De acordo com Bóia, está aqui implícita uma profunda revoluçáo na forma de conceber o papel do Estado, que resulta do facto dos governos da nova direita, hegemónica na década de oitenta, terem "elaborado uma 'policy mix' centrada na promoção da cultura empresarial no campo educativo (...) procurando transferir o ónus da educação para as pessoas singulares (...) [pela] adopção de uma política baseada na democracia de mercado" (Bóia, 2003, pp. 90-93). Também Torres assinala, acerca do impacto geral do que designa por movimento direitista na educação, que esta nova visão "se distancia da ideia singular de uma educação para a democracia, como inicialmente defendida pelo liberalismo [social] e sua contrapartida pedagógica, o progressismo. Daí a ênfase sobre a qualidade da educação, a excelência, e sobretudo o apoio à ciência e à tecnologia" (Torres, 2001, p. 66). No geral a educação de adultos resultante do modelo reformista neoliberal pode ser vista como significando uma retracçáo educacional notável e sem precedentes, representando uma época negra na história da educação de adultos, na medida em que como enfatiza Lima, "a formaçáo e a aprendizagem ao longo da vida chegam a ser objecto de um tão profundo processo de instrumentalização com vista à eficácia económica e à performatividade competitiva que parecem frequentemente reduzidas a estratégias vocacionalistas e a técnicas de gestão de recursos humanos, pouco ou nada se assemelhando a formas e processos de educação" (Lima, 2003, p. 136).

Ora, as vincadas diferenças entre cada um destes três tipos de modelos de produção de políticas sociais permite identificar os distintos pontos de partida principais a nível políticoideológico a partir dos quais se elaboram as políticas públicas de educação de adultos, o que, por seu turno, possibilita uma melhor compreensão crítica das linhas fundamentais com que se desenvolve o debate actual sobre políticas públicas. Sustentámos que, quer se queira quer não, no centro deste debate estão inevitavelmente, como salienta Afonso, os valores específicos, e desde uma perspectiva humanista inalienáveis, do domínio público, entre os quais há a destacar fundamentalmente a igualdade, a justiça e a cidadania, valores que têm vindo, no contexto actual da redefinição do papel do Estado, a ser "subvertidos e substituídos por influência das políticas neoliberais no campo da educação" (Afonso, 2002, p. 81). Aqui, precisamente, se localiza, de acordo com Lenhardt e Offe (1984), o conflito político e teórico-político, que como resultado do "movimento direitista em educação" a que se refere Torres (2001), está no cerne da actual transformação (mutação?) observável hoje no campo da educação de adultos, que a está claramente a reduzir nos seus aspectos 
humanistas tradicionais. Um fenómeno traduzido por inovaçóes sócio-políticas que estão a ocorrer no sector, a um ritmo assinalável, em cujo contexto as novas medidas de política educativa se radicalizam visivelmente, em larga medida como consequência da "cientificação crescente da política social" (Lenhardt e Offe, 1984, p. 48) que caracteriza a nova ordem educacional emergente. Trata-se de uma nova realidade cujo desvelamento crítico pressupóe, no nosso entender, a conjugação de uma reflexão histórico-estrutural (cf. Morrow e Torres, 1997 , p. 313) com aquele tipo de engajamento intelectual desenvolvido no pensamento freiriano. É neste sentido, que ao debate hodierno sobre as políticas públicas de educação de adultos fazemos, também, corresponder indagaçóes mais gerais, enquadradoras da percepção dominante acerca da nova ordem educacional, como as que sugeriram, há mais de vinte anos, Lenhardt e Offe neste troço mais longo da sua reflexão, que vale a pena citar:

\begin{abstract}
"continuará a política social académica, ignorando a evidência dos fatos, e seguindo o exemplo da teoria económica e jurídica, ou de uma 'policyscience' enfeudada ao Estado, a sustentar a concepção de que a política estatal é capaz, graças a seu saber, de gerar politicas 'mais eficientes', 'mais efetivas', 'mais adequadas', 'mais corretas' ou mesmo 'socialmente mais justas? Ou poderia ela libertar-se desse equivoco tecnocrático, operando em vez disso com base na evidência de que não são em absoluto os 'policy outputs', com suas estruturas institucionais e legais, que definem o 'impacto' da politica social, mas que são as relaçôes sociais de poder, de coerção e de ameaça, legal e politicamente sancionadas, bem como as oportunidades correspondentes da realização de interesses, que determinam o grau de 'justiça social' que a politica social tem condiçôes de produzir?” (Lenhardt e Offe, 1984, p. 48).
\end{abstract}

Um equivoco tecnocrático que, de resto, continua a gerar inovaçóes no campo oficial e público da educação de adultos (hoje cabal, mas arriscadamente, ressemântizada nos discursos hegemónicos enquanto educação e formação de adultos ${ }^{1}$ ), que se vê frequentemente confrontada com modelos impostos ${ }^{2}$ numa lógica de cima para baixo, e que à semelhança do que tem acontecido nas inovações introduzidas na administraçáo e gestáo das escolas do sistema educativo formal, nascem igualmente de "propostas de especialistas em ciências da educação - às quais se seguiram pareceres e discussóes públicas, sindicais e políticas - mas em nenhum caso estes modelos poderão ser representados como o resultado de uma mobilização social e pedagógica à qual o Estado não teria podido ser indiferente" (Afonso, 2002, p. 80). Ao entendermos as políticas educativas como políticas sociais se percepciona, pois, mais facilmente que as mudanças verificadas no campo da educação de adultos, crescentemente inscritas no paradigma da aprendizagem ao longo da vida, são parte constituinte e operante da estratégia de reforma do modelo do Estado-Providência, no âmbito da qual se "visa a implementação de uma série de reformas políticas e administrativas com o intuito de pôr em prática o que passou a ser referido como uma nova gestão pública (new public management)" (id., ibid, p. 83).

Sobre isto ver, por exemplo, Barros, R. (no prelo).

2 Sustentámos, com base nos dados recolhidos e interpretados noutro lugar (Barros, 2009; 2011), que a recente introdução do Sistema Nacional de Reconhecimento, Validação e Certificação de Competências no campo da educação de adultos em Portugal ilustra paradigmaticamente esta situação de equívoco tecnocrático, náo obstante as especificidades a ter em conta num país semiperiférico do sul da Europa. 
A perspectiva crítica adoptada, e assim referenciada, permite-nos igualmente reflectir acerca do próprio processo político de produção de decisôes educativas no campo da educação de adultos, constatando a emergência de um quadro novo de forças em interacção no âmbito da regulaçáo social, que se traduz no surgimento quer do terceiro sector quer do quase-mercado em educação. Trata-se de um novo formato, ainda em construção, para o espaço público, no qual o triângulo em permanente tensão constituído pela relaçáo entre o Estado, a sociedade civil e o mercado se tem vindo a reconfigurar, dando lugar a novos híbridos que parecem possibilitar uma recalibragem entre os três princípios em que assenta o pilar da regulação social, que estando, por sua vez em relação dialéctica com o pilar da emancipaçáo social, constituem, como se sabe, a base do contrato social da modernidade ocidental e, portanto, a base da continuidade ou da transformação da normalidade quotidiana instituída pela forma política do Estado Capitalista Democrático.

Argumenta-se neste texto que as novas políticas de educação e formação de adultos (EFA) fazem, por isso, parte da nova estratégia de reformulação da provisão social e educativa, que ao dar protagonismo aos novos híbridos no processo de elaboração e formulaçáo das políticas educativas do sector traduz e visibiliza, na verdade, novas formas de actuação do Estado, que, paradoxalmente, se tornou mais forte no contexto da matriz de governação neoliberal. É neste sentido que ganham importância, por exemplo, as abordagens que tomam como objecto de análise os mecanismos de quase-mercado na educação de adultos, na medida em que, como afirma Afonso, os quase-mercados são "uma espécie de exlibris do carácter híbrido público/privado, Estado/mercado, inerente às políticas adoptadas na fase de expansão neoliberal" (Afonso, 2002, p. 86). Trata-se de quase-mercados existentes hoje em diversas esferas do bem-estar social, que diferem dos mercados convencionais na medida em que, nos termos definidos por LeGrand e Bartlett (1993), são mercados na medida em que promovem a concorrência entre distintas instituiçóes e fornecedores de serviços sociais que anteriormente eram monopólio do Estado, mas são concomitantemente apenas quase uma vez que não se regem plenamente pela lógica pura da maximização dos lucros. Particularmente na esfera da educação pública, como nota Dale, o termo mercado ainda é mais conotativo do que denotativo, pois "o que está em questão são novas formas e combinaçóes de financiamento, fornecimento e regulação da educaçáo" (Dale, 1994, pp. 110-111). Indo no mesmo sentido a interpretaçáo de Griffin para o campo da educação de adultos, quando afirma que "a literatura vigente da aprendizagem ao longo da vida no modelo de reforma social reflecte este quase-mercado e náo o de um mercado económico no sentido clássico ou laissez-faire" (Griffin, 1999b, p. 441). A emergência de quase-mercados, e não de mercados toutcour, na educação de adultos, que segundo Dale (1994) é derivada da necessidade estratégica da manutenção do controlo estatal sobre a actividade educativa, não significa, no entanto, que na nova ordem educacional, que está a caracterizar o início do século XXI, não se verifique, segundo nota Mesquita, um expressivo "reforço das posiçóes que, defendendo embora o fornecimento pelo Estado de um nível mínimo de serviços educativos a todos os cidadãos, propugnam, por razóes de 'liberdade de escolha' e de 'optimização da eficiência', o incremento de mercados ou quase-mercados educativos e o fornecimento privado, a par do Estado, dos mesmos serviços educativos" (Mesquita, 2000, p. 75).

Posto isto, o que há a realçar, neste momento da nossa reflexão, é que independentemente das especificidades com que estes novos híbridos se manifestam em pontos diversos do sistema mundial moderno, a sua emergência, tanto ao nível dos quase-mercados 
como ao nível do terceiro sector, veio introduzir, em boa medida, um patamar novo de complexidade na análise e compreensão do processo político de produção de políticas sociais e educativas nas sociedades capitalistas hodiernas. $\mathrm{O}$ argumento é que neste processo, a importância do papel do Estado, como actor principal, no âmbito genérico da elaboração das políticas públicas manteve-se intacta, se é que a sua autoridade não saiu mesmo reforçada, como sugerem Morrow e Torres (1997), mas que o clima geral de elaboração da política social, e particularmente da política educativa, sofreu alterações profundas e substanciais em grande parte dos seus pressupostos processuais e políticoideológicos. Estas alteraçôes processuais, são agora de um tipo novo que exploram politicamente, segundo Dale, "uma base racional que permite que determinadas coisas sejam feitas através da acção privada, enquanto as mesmas coisas seriam bloqueadas se a única forma de as realizar envolvesse o governo num papel activo" (Dale, 1994, p. 114). Neste sentido, trata-se de uma base sócio-política que possibilita ao Estado modificar, principalmente, os termos em que a sua acção de regulação é exercida e percepcionada, contornando, agora, mecanismos de concertação que tinham sido democraticamente instituídos, na medida em que "o trabalho de persuasão - ou promoção - pode ser minimizado pela adopção de mecanismos políticos que conduzam a que elementos-chave da política sejam implantados como faitsacomplis sem nunca terem sido formalmente considerados no forum político" (id., ibid.). Ora, parece-nos ser, precisamente, nesta dimensão das transformaçóes ocorridas no modo de conceber as políticas educativas, que o paradigma da aprendizagem ao longo da vida pode ser pensado, actualmente, quer como uma evidência quer como um instrumento da redefinição do papel do Estado, cuja lógica de actuação ao nível da elaboração da política educativa parece ter se deslocado definitivamente "da maneira antiga de fazer políticas rumo à formação de estratégias", (Griffin, 1999b, p. 450), exigindo assim também novos esforços de análise "para pensar em termos de estratégias de aprendizagem global em vez de políticas educativas enquanto tal" (Griffin, 2002, p. 43).

Concluímos reiterando, pois, que pensar as políticas educativas como políticas sociais num quadro de redefiniçáo do papel do Estado revela-se, pelo que foi explanado, uma perspectiva pertinente para o estudo das políticas educativas no campo da educação de adultos. Não obstante, se esta perspectiva, nos moldes aqui referenciados, nos permite compreender num plano macro-analítico que hodiernamente "delegando em decisóes individuais que, em conjunto, têm efeitos políticos substanciais, os legisladores não diminuem a extensão em que dirigem a política, mas, encobertamente, mudam a sua direcção" (Dale, 1994, p. 114), já num plano mega-analítico haverá que recorrer também a outros suportes teórico-conceptuais que facilitem a compreensão da nova ordem educacional a um nível em que a produção das políticas sociais se interrelaciona com modos deprodução de globalização que em conjunto criaram as condiçôes para a emergência de uma nova forma de governação educacional a que há, de igual forma, mas noutro lugar que não este, que atender. 


\section{Referências Bibliográficas}

Afonso, A. J. (2002). A(s) Autonomia(s) da Escola na Encruzilhada entre o Velho e o Novo Espaço Público. In Licínio Lima \& Almerindo Afonso. Reformas da Educação Pública - Democratização, Modernização, Neoliberalismo (pp. 75-90). Porto: Ediçóes Afrontamento.

Althusser, L. (1970). Ideologia e Aparelhos Ideológicos do Estado. Lisboa: Editorial Presença.

Antunes, F. (1998). Politicas Educativas para Portugal, anos 80-90 - O Debate acerca do Ensino Profissional na Escola Pública. Lisboa: Instituto de Inovação Educacional.

Barros, R. (2009). Politicas para a Educação de Adultos em Portugal-A Governação Pluriescalar da «Nova Educação e Formação de Adultos» (1996-2006). Braga: Universidade do Minho. [Tese de Doutoramento].

Barros, R. (2011). A Criação do Reconhecimento de Adquiridos Experienciais (RVCC) em Portugal-Uma Etnografia Crítica em Educação de Adultos. Lisboa: Chiado Editora.

Barros, R. (no prelo). Genealogia dos Conceitos em Educação de Adultos: Da Educação Permanente à Aprendizagem ao Longo da Vida - Um estudo sobre os fundamentos político-pedagógicos da prática educacional.

Bóia, J. M. P. (2003). Educação e Sociedade - Neoliberalismo e os Desafios do Futuro. Lisboa: Edições Sílabo.

Dale, R. (1994). A Promoção do Mercado Educacional e a Polarização da Educação. Educação, Sociedade e Culturas, 2, 109-139.

Dubar, C., \& Gadéa, C. (2001). Sociologia da Formação Pós-Escolar. In Philippe Carré \& Pierre Caspar (Dir.). Tratado das Ciências e das Técnicas da Formação (pp. 143-160). Lisboa: Instituto Piaget.

Griffin, C. (1999a). Lifelong Learning and Social Democracy. International Journal of Lifelong Education, 5 (18), 329-342.

Griffin, C. (1999b). Lifelong Learning and Welfare Reform.International Journal of Lifelong Education, 6 (18), 431-452.

Griffin, C. (2002). From Education Policy to Lifelong Learning Strategies. In Peter Jarvis (ed.). The Age of Learning - Education and the Knowledge Society (pp. 41-54). London: KoganPage.

Jarvis, P. (1989). Sociología de la Educación Continua y de Adultos. Barcelona: Editorial Cooperativa El Roure.

Le Grand, J. \& Bartlett, W. (1993). Quasi-Markets and Social Policy: The Way Forward? In Julian Le Grand \& Will Bartlett (Ed.). Quasi-Markets and Social Policy (pp. 202-220). London: TheMacMillanPress.

Lenhardt, G. \& Offe, C. (1984). Teoria do Estado e Política Social - Tentativas de Explicação Político-Sociológica para as Funções e os Processos Inovadores da Política Social. In Claus Offe Problemas Estruturais do Estado Capitalista (pp. 10-53). Rio de Janeiro: Tempo Brasileiro.

Lima, L. C. (1994). Inovaçáo e Mudança em Educação de Adultos - Aspectos Educacionais Organizacionais e de Política Educativa. Educação de Adultos -Forum I, 59-73.

Lima, L. C. (2000). Educação de Adultos e Construçâo da Cidadania Democrática: Para uma Crítica do Gerencialismo e da Educação Contábil. Educação de Adultos -Forum II, 237-255.

Lima, L. C. (2003). Formação e Aprendizagem ao Longo da Vida: Entre a Mão Direita e a Esquerda de Miró. In Cruzamentos de Saberes Aprendizagens Sustentáveis, (pp. 129-148). Lisboa: Fundação Calouste Gulbenkian.

Lima, L. C. (2004). Do Aprender a Ser à Aquisição de Competências para Competir: Adaptação, Competitividade e Performance na Sociedade da Aprendizagem. Revista Galego-Portuguesa de Psicoloxia e Educación, 9 (11), 9-18.

Mesquita, L. (2000). Educação e Desenvolvimento Económico - Contribuição para o Estudo da Natureza Presente de uma Relação. Lisboa: Instituto de Inovação Educacional.

Morrow, R. \& Torres, C. A. (1997). Teoria Social e Educação - Uma Crítica das Teorias da Reprodução Social e Cultural. Porto: Ediçōes Afrontamento.

Oliveira, D. A. \& Duarte, A. (2005). Política Educacional como Política Social: Uma Nova Regulação da Pobreza. Perspectiva, 23 (2), 279-300.

Pöggeler, F. (1990). The State and Adult Education. In Franz Pöggeler (ed.). The State and Adult Education Historical and Systematical Aspects (pp. 15-20). Frankfurt am Main: Verlag Peter Lang.

Torres, C. A. (2001). Democracia, Educação e Multiculturalismo - Dilemas da Cidadania em um Mundo Globalizado. Rio de Janeiro: Editora Vozes. 
Série Documentos

Imprensa da Universidade de Coimbra

Coimbra University Press

2011

- U

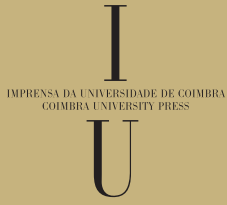

